\title{
Maternofetal Outcome of Postdated Pregnancy: A Retrospective Analysis
}

\author{
Nikita Gandotra ${ }^{1}$, Heena Gupta ${ }^{2}$
}

\begin{abstract}
Background: Pregnancy beyond dates is one of the most frequent clinical dilemmas faced by the obstetrician. Postdated pregnancy is a universally accepted indication for antenatal fetal monitoring because of the increased risk of antepartum fetal demise with advancing gestational age. Method: This study was a retrospective observational study for 1 year to analyze the maternal and fetal outcomes of postdated pregnancies. Data were collected from hospital records and analyzed.

Results: In the present study, the incidence of postdated pregnancy was found to be $6.23 ; 0.46 \%$ were spontaneous vaginal deliveries, and $30 \%$ were induced deliveries. The lower segment cesarean section (LSCS) was done in $21 \%$ of patients and failed induction being the most common indication for LSCS. Maternal complications were seen in 12 (12\%) cases, and fetal complications were found in 13 (13\%) cases.

Conclusion: Management protocol for postdated pregnancy is fetal surveillance for prolonged pregnancy, induction of labor, and proper monitoring of labor during intrapartum care.

Keywords: Maternal morbidity, Perinatal morbidity, Postdated.

Journal of Health Sciences \& Research (2021): 10.5005/jp-journals-10042-1098
\end{abstract}

\section{INTRODUCTION}

The term delivery is defined as that occurring between 259 and 294 days of pregnancy from the last menstrual period (LMP). Post-term or prolonged pregnancy is the one that extends to or beyond 42 weeks or 294 days from the first day of the LMP and has an incidence of $5 \%$ to $10 \% .{ }^{1}$ A postdated pregnancy is the one that extends to or beyond 40 weeks or 280 days from the first day of the LMP and has an incidence of 4 to $14 \% .^{2}$ Postdated and post-term pregnancies always carry a high risk, as there is a possibility of fetal distress and fetal death due to progressive fetal hypoxia following placental insufficiency. Prolongation of pregnancy beyond 40 weeks occurs more frequently, in about 1 out of 10 pregnancies. ${ }^{2}$

The following definitions describe the subgroups of term pregnancy':

- Post-term $-\geq 42+0$ weeks of gestation (i.e., $\geq 294$ days from the first day of the LMP and $\geq 14$ days from the estimated day of delivery)

- Late-term $-41^{+0}$ to $41^{+6}$ weeks of gestation

- Full-term $-39^{+0}$ to $40^{+6}$ weeks of gestation

- Early term $-37^{+0}$ to $38^{+6}$ weeks of gestation

The incidence of postdated pregnancy depends on whether the calculation is based on the history or early pregnancy ultrasonography is also used to find the EDD., ${ }^{3,4}$ Postdated pregnancy is associated with an increased risk of fetal and neonatal mortality and morbidity as well as an increased maternal morbidity. ${ }^{5,6}$ Exact etiology is not known, but some risk factors are associated with postdated pregnancy like parity, maternal age, history of post-term pregnancy, genetics, and obesity. ${ }^{7,8}$

Postdated pregnancy is associated with an increased risk of postnatal mortality and morbidity, including meconium aspiration syndrome (MAS), oligohydramnios, macrosomia, fetal birth injuries, septicemia, rate of nonreassuring fetal heart rate, fetal distress in labor, and maternal complication increased cesarean
${ }^{1}$ Department of Obstetrics and Gynaecology, GMC Jammu, Jammu and Kashmir, India

${ }^{2}$ Department of Anaesthesia, GMC Jammu, Jammu and Kashmir, India

Corresponding Author: Nikita Gandotra, Department of Obstetrics and Gynaecology, GMC, Jammu, Jammu and Kashmir, India, Phone: +91 9796462929, e-mail: nikigandotra12@gmail.com

How to cite this article: Gandotra N, Gupta H. Maternofetal Outcome of Postdated Pregnancy: A Retrospective Analysis. J Health Sci Res 2021;12(1):1-4.

Source of support: Nil

Conflict of interest: None

rates, cephalopelvic disproportion, cervical tear, dystocia, and postpartum hemorrhage. ${ }^{9}$ Management protocol for postdated pregnancy is fetal surveillance for prolonged pregnancy, induction of labor, and proper monitoring of labor during intrapartum care. ${ }^{10}$

The perinatal mortality rate at $\geq 42$ weeks of gestation is twice the rate at term, increasing fourfold at 43 weeks and five- to sevenfold at 44 weeks. ${ }^{11-16}$ Neonates born at $\geq 41$ weeks of gestation experience a one-third greater risk of neonatal mortality than term neonates born at 38 to 40 weeks of gestation. ${ }^{17}$

Perinatal mortality increases as pregnancy extends beyond full-term, particularly after 41 weeks, due to increase in both nonanomalous stillbirths and early neonatal deaths. ${ }^{17,18}$ Intrauterine infections, placental insufficiency due to placental aging, and cord compression leading to fetal hypoxia, asphyxia, and meconium aspiration are thought to contribute to the excess perinatal deaths. ${ }^{19}$

\section{Materials and Methods}

This study was carried out retrospectively in the Department of Obstetrics and Gynaecology, GMC Hospital, Jammu. A total of 100 patients beyond 40 weeks of gestation admitted in the Obstetrics 
and Gynaecology Department were selected in the study group cases by lottery method. It was a retrospective observational study for 1 year from July 2019 to July 2020, and participants willing to participate and fulfilling the inclusion and exclusion criteria were included in the study period.

\section{Inclusion Criteria}

- Pregnant women more than 40 weeks of gestation (last three menstrual cycles regular, not used contraceptive pills for the past 3 months, and not conceived during lactational amenorrhea)

- Singleton pregnancy with vertex presentation.

\section{Exclusion Criteria}

- High-risk pregnancies like diabetes, antepartum hemorrhage, premature rupture of membranes and pregnancy-induced hypertension, heart disease, chronic hypertensive disease, and chronic renal disease

- Previous cesarean sections

- Congenital anomalies

- Multiple gestation

- Nonvertex presentation

The data were collected from the hospital records of pregnant females as per the inclusion and exclusion criteria. The booking status of cases was also noted. Maternal and fetal outcomes were tabulated.

\section{Results}

The total number of deliveries over 1-year study period was 23,409 ; out of which 1460 patients were beyond 40 weeks of gestation, so the incidence of postdated pregnancy was $6.23 \%$ at our center. Of the total 100 patients selected, $64 \%$ were in $40-40$ weeks $6 \mathrm{D}$ group, $26 \%$ were in $41-41$ weeks $6 \mathrm{D}$ group, and $10 \%$ were in $\geq 42$ weeks group (Table 1).

The majority of patients (66\%) were in the age-group of 20-35 years, and only 5\% of patients was in the age-group $>35$ years. Sixty-three percent of patients were primigravida, while thirty-seven percent of patients were multigravida in our study. The number of unbooked cases was more in this study (61\%) (Table 2).

At our hospital setup, induction is done at $40+$ weeks because of loss of follow-up of patients and perinatal complications associated with post-term pregnancy.

Of the total 100 patients beyond 40 weeks of gestation in our study, $46 \%$ delivered with spontaneous onset of labor, $30 \%$ delivered after induction, and $21 \%$ had a cesarean section.

There were $3(3 \%)$ instrumental deliveries in our study (Table 3).

Out of a total of 100 patients, 30 (30\%) patients needed induction of labor; out of which $60 \%$ were induced by combined intracervical Foley's catheter and tablet misoprostol (25 ug), $13.4 \%$ with only intracervical Foley's catheter, $16.6 \%$ with tablet misoprostol ( $25 \mathrm{ug}$ ) up to four doses maximum, and $10 \%$ patients induced with oxytocin, according to Bishop score (Table 4).

Twenty-one patients underwent cesarean section in our study for various indications. Failed induction was the leading (33.3\%) indication for cesarean section in our study followed by fetal distress in $19.3 \%$ of patients (Table 5).

Among all patients (3\%) who needed instrumental delivery, 2 (66.6\%) participants delivered by the assistance of outlet forceps and 1 (33.3\%) participant needed the assistance of vacuum (Table 6).
Table 1: Gestational age distribution

\begin{tabular}{lcc}
\hline Gestational age & Number & Percentage (\%) \\
\hline $40-40$ weeks 6 days & 64 & 64 \\
$41-41$ weeks 6 days & 26 & 26 \\
$\geq 42$ weeks & 10 & 10 \\
Total & 100 & 100 \\
\hline
\end{tabular}

Table 2: Demographic characteristics

\begin{tabular}{lcc}
\hline Age (years) & Number & Percentage (\%) \\
\hline $20-25$ & 66 & 66 \\
$25-30$ & 16 & 16 \\
$30-35$ & 13 & 13 \\
$>35$ & 5 & 5 \\
Total & 100 & 100 \\
Parity & & \\
Primigravida & 63 & 63 \\
Multigravida & 37 & 37 \\
Total & 100 & 100 \\
Booking status & & \\
Unbooked & 61 & 61 \\
Booked & 39 & 39 \\
Total & 100 & 100 \\
\hline
\end{tabular}

Table 3: Mode of delivery

\begin{tabular}{lcc}
\hline Mode of delivery & Number & Percentage (\%) \\
\hline Spontaneous delivery & 46 & 46 \\
Induced delivery & 30 & 30 \\
Cesarean section & 21 & 21 \\
Instrumental delivery & 3 & 3 \\
Total & 100 & 100 \\
\hline
\end{tabular}

Table 4: Type of induction

\begin{tabular}{lcc}
\hline Type of induction & Number & Percentage (\%) \\
\hline Tab misoprostol (25 ug) & 5 & 16.6 \\
Intracervical Foley's & 4 & 13.4 \\
Foley's + misoprostol & 18 & 60 \\
Oxytocin & 3 & 10 \\
Total & 30 & 100 \\
\hline
\end{tabular}

Table 5: Indication of LSCS $(N=21)$

\begin{tabular}{lcc}
\hline Indication & Number & Percentage (\%) \\
\hline Failed induction & 7 & 33.3 \\
Fetal distress & 4 & 19.3 \\
Cephalopelvic disproportion & 2 & 9.5 \\
Transverse lie & 1 & 4.7 \\
Absent liquor & 2 & 9.5 \\
Nonprogression of labor & 3 & 14.2 \\
Severe oligohydramnios & 2 & 9.5 \\
Total & 21 & 100 \\
\hline
\end{tabular}


Table 6: Instrumental deliveries

\begin{tabular}{llc}
\hline Type & Number & Percentage \\
\hline Outlet forceps & 2 & 66.6 \\
Vacuum & 1 & 33.4 \\
Total & 3 & 100 \\
\hline
\end{tabular}

Table 7: Birth weight

\begin{tabular}{lccc}
\hline Birth weight $(\mathrm{kg})$ & $\begin{array}{c}40-40 \text { weeks } \\
6 \text { days }(n=64)\end{array}$ & $\begin{array}{c}41-41 \text { weeks } \\
6 \text { days }(n=26)\end{array}$ & $\begin{array}{c}>42 \text { weeks } \\
(n=10)\end{array}$ \\
\hline$<2.5$ & $4(6.2 \%)$ & $3(11.5 \%)$ & $2(2)$ \\
$2.5-3.5$ & $58(90.6 \%)$ & $22(84.7 \%)$ & $5(50)$ \\
$>3.5$ & $2(3.2 \%)$ & $1(3.8 \%)$ & $3(30)$ \\
Total & $64(100 \%)$ & $26(100 \%)$ & $10(100)$ \\
\hline
\end{tabular}

\section{Fetal Complications}

The majority of the babies born to participants weighed between 2.5 to $3.5 \mathrm{~kg}$ in our study (Table 7 ).

In the present study, 13 neonates were admitted to NICU after delivery (Table 8). The primary reason was respiratory distress with meconium-stained liquor in seven babies followed by low birth weight (LBW) in three babies, respiratory distress syndrome (RDS) in two babies, and hyperbilirubinemia in one baby. There was one neonatal death and two stillbirths (Table 9).

Maternal complications were present in 12 cases. Postpartum hemorrhage was found in five (5\%) cases, perineal tear was present in three (3\%) cases, wound infection was found in two (2\%) cases, and shoulder dystocia was found in two (2\%) cases. There was one neonatal death in this study due to MAS and two stillbirths in our study (Table 10).

\section{Discussion}

The present study was conducted to find out the incidence of maternal complications, perinatal mortality, and morbidity in postdated pregnancies. Total cases were 100, which were enrolled based on inclusion and exclusion criteria.

Pregnancies that reach $41^{+0}$ weeks of gestation can be induced or managed expectantly with ongoing fetal assessment and intervention if spontaneous labor does not occur by a predefined gestational age or fetal assessment is not reassuring. In the low-risk postdated pregnancy, both of these approaches are associated with low absolute rates of adverse outcome. ${ }^{20}$ Patients should be counseled about what these approaches involve (labor induction with/without cervical ripening agents, type and frequency of antepartum fetal, and maternal monitoring) and the maternal and fetal benefits and risks of both approaches.

Expectant management is the alternative to induction. Expectantly managed pregnancies typically undergo twiceweekly fetal assessment beginning at $41^{+0}$ weeks (or shortly thereafter), with intervention if spontaneous labor does not begin by a predefined gestational age or fetal assessment testing is abnormal. ${ }^{21,22}$ Either a nonstress test plus assessment of amniotic fluid volume or the biophysical profile can be used for antenatal monitoring; there is no convincing evidence that one method is superior to the other. ${ }^{23}$ The American College of Obstetricians and Gynecologists recommends to induce labor by $42^{+6}$ weeks of gestation in all pregnancies. ${ }^{24}$

\begin{tabular}{lc} 
Table 8: Indications for NICU admission $(n=13)$ \\
\hline Indication & Number \\
\hline MAS with RDS & 7 \\
LBW & 3 \\
RDS & 2 \\
Hyperbilirubinemia & 1 \\
None & 87 \\
Total & 100 \\
\hline
\end{tabular}

Table 9: Other fetal complications

\begin{tabular}{lc}
\hline Fetal complications & Number \\
\hline Apgar $<6$ & 5 \\
IUGR & 3 \\
MAS & 7 \\
NICU admission & 13 \\
Stillbirth & 2 \\
\hline
\end{tabular}

Table 10: Maternal and perinatal morbidity

\begin{tabular}{lc}
\hline Maternal & Number (12) \\
\hline PPH & 5 \\
Perineal tear & 3 \\
Shoulder dystocia & 2 \\
Wound infection & 2 \\
None & 88 \\
Perinatal & Number (3) \\
Stillbirth & 2 \\
Neonatal death & 1 \\
\hline
\end{tabular}

After one postdated pregnancy, the risk of a second postdated birth is increased two- to fourfold; the risk of recurrence is even higher after two prior postdated pregnancies. ${ }^{25,26}$

In our study, the majority of patients $(66 \%)$ were in the agegroup of 20 to 35 years, $63 \%$ of patients were primigravida, and the number of unbooked cases was more in this study (61\%). These were similar to studies conducted by Verma et al. ${ }^{27}$ and Kandalgaonkar et al. ${ }^{28}$

Induction of labor was done at $40+$ weeks because of loss of follow-up of patients and perinatal complication associated with post-term pregnancy in our hospital. Of the total 100 patients beyond 40 weeks of gestation in our study, 30\% delivered after induction and the most common means of induction was by combined intracervical Foley's and misoprostol ( $25 \mathrm{ug}$ ). Then, 36.5\% of patients were induced in the study done by Kandalgaonkar et al. ${ }^{28}$

In these studies, maximum women (64\%) were in between $40^{+1}$ to 41 weeks of gestation age, $26 \%$ were in between 41 to 42 weeks of gestation age, and $10 \%$ were in between more than 42 weeks of gestation age, similar to the study conducted by Singh et al. ${ }^{29}$ The number of patients who underwent cesarean section was 21 in our study, and the most common indication for cesarean section was failed induction (33.3\%), similar to studies conducted by Kandalgaonkar et al. ${ }^{28}$ and Singh et al. ${ }^{29}$ In the study by Akhtar et al., ${ }^{30}$ cesarean section was done in view of fetal distress in $32 \%$ cases, nonprogress of labor in $25.3 \%$ cases, and failure of induction in $24 \%$ cases.

In this study, the most common (5\%) complication was postpartum hemorrhage (PPH), similar to the study conducted 
by Singh et al. ${ }^{29}$ There was no maternal mortality. There was one neonatal death in this study due to MAS and two stillbirths in our study.

Though the correct choice of management remains controversial, according to the present study, it seems reasonable to induce labor at $40+$ weeks of gestation with strict intrapartum monitoring as maternal and perinatal complications were lesser as compared to induction later than this period of gestation. It is also done because of the loss of follow-up of patients and perinatal complications associated with post-term pregnancy.

\section{Conclusion}

Postdated pregnancies require early identification and effective and proper planned management. The adverse outcome can be reduced by counseling for an antenatal checkup and follow-up during pregnancy and proper monitoring during labor. More training for peripheral health worker is required for the calculation of accurate dating, making a diagnosis, and proper management to reduce its incidence. Postdated pregnancy is associated with fetal, neonatal, and maternal complications, including morbidity and perinatal mortality. The use of routine ultrasound for dating in the first trimester has decreased the overall rate of postdated pregnancy.

\section{References}

1. ACOG Committee Opinion No 579: definition of term pregnancy. Obstet Gynecol 2013;122:1139. DOI: 10.1097/01. aog.0000437385.88715.4a.

2. Fernando A. Prolonged pregnancy. In: Nasim S (ed) Practical guide to high risk pregnancy and delivery. Noida: Elsevier; 2008, pp. 255-256.

3. Eik-Nes SH, Okland O, Aure JC, et al. Ultrasound screening in pregnancy: a randomized controlled trial. Lancet 1984;567:1347. DOI: 10.1016/s0140-6736.

4. Ingemarsson I, Hedén L. Cervical score and onset of spontaneous labor in prolonged pregnancy dated by second-trimester ultrasonic scan. Obstet Gynecol. 1989 Jul;74(1):102-5. PMID: 2660039.

5. Olesen AW, Westergaard JG, Olsen J. Perinatal and maternal complications related to post term delivery: a national registerbased study, 1978-1993. Am J Obstet Gynecol 2003;189:222-227. DOI: 10.1067/mob.2003.446.

6. Caughey $A B$, Stotland NE, Washington AE. Maternal obstetric complications of pregnancy are associated with increasing gestational age at term. Am J Obstet Gynecol 2007;196:155.e1. DOI: 10.1016/j.ajog.2006.08.040.

7. Divon MY, Haglund B, Nisell H, et al. Fetal and neonatal mortality in the post term pregnancy: the impact of gestational age and fetal growth restriction. Am J Obstet Gynecol 1998;178(4):726-731. DOI: 10.1016/s0002-9378(98)70482-x.

8. Van Eyk N, Allen LM, Sermer M, et al. Obstetric outcome of adolescent pregnancies. J Pediatr Adolescent Gynecol 2000;13(2):96. DOI: 10.1016/s1083-3188(00)00033-4.

9. Cunningham FG, Leveno KJ, Bloom SL, et al. Post-term pregnancy. In: William's obstetrics. 23rd ed. New York: McGraw-Hill Companies; 2010, pp. 832-841.

10. Mandruzzato G, Alfirevic Z, Chervenak F, et al. Guidelines for the management of post term pregnancy. J Perinat Med 2010;38:111-119. DOI: 10.1515/jpm.2010.057.

11. Feldman GB. Prospective risk of stillbirth. Obstet Gynecol. 1992 Apr;79(4):547-53. PMID: 1553174.
12. Bakketeig LS, Bergsjo P. Post-term pregnancy: magnitude of the problem. In: Enkin M, Keirse MJ, Chalmers I (eds) Effective care in pregnancy and childbirth. Oxford: Oxford University Press, 1989.

13. Nakling J, Backe B. Pregnancy risk increases from 41 weeks of gestation. Acta Obstet Gynecol Scand 2006; 85:663. DOI: 10.1080/00016340500543733.

14. Divon MY, Haglund B, Nisell $\mathrm{H}$, et al. Fetal and neonatal mortality in the post term pregnancy: the impact of gestational age and fetal growth restriction. Am J Obstet Gynecol 1998;178:726. DOI: 10.1016/ s0002-9378(98)70482-x.

15. De Los Santos-Garate AM, Villa-Guillen M, Villanueva-García D, et al. Perinatal morbidity and mortality in late-term and post-term pregnancy. NEOSANO perinatal network's experience in Mexico. J Perinatol 2011;31:789. DOI: 10.1038/jp.2011.43.

16. Bruckner TA, Cheng YW, Caughey AB. Increased neonatal mortality among normal-weight births beyond 41 weeks of gestation in California. Am J Obstet Gynecol 2008;199:421.e1. DOI: 10.1016/j. ajog.2008.05.015.

17. Heuser C, Manuck T, Hossain S, et al. Non-anomalous stillbirth by gestational age: trends differ based on method of epidemiologic calculation. J Matern Fetal Neonatal Med 2010; 23:720. DOI: 10.3109/14767050903387086.

18. Hannah ME, Hannah WJ, Hellmann J, Hewson S, Milner R, Willan Rand the Canadian Multicenter Post-term Pregnancy Trial Group (1992) Induction of labor as compared with serial antenatal monitoring in post-term pregnancy. A randomized controlled trial. New Eng J Med 326:1587-1592.

19. Maiti K, Sultana Z, Aitken RJ, et al. Evidence that fetal death is associated with placental aging. Am J Obstet Gynecol 2017;217:441. e1. DOI: 10.1016/j.ajog.2017.06.015.

20. Middleton P, Shepherd E, Morris J, et al. Induction of labour at or beyond 37 weeks' gestation. Cochrane Database Syst Rev 2020;7:CD004945. DOI: 10.1002/14651858.CD004945.pub5.

21. Guidetti DA, Divon MY, Langer O. Postdate fetal surveillance: is 41 weeks too early? Am J Obstet Gynecol 1989;161:91. DOI: 10.1016/00029378(89)90240-8.

22. Bochner CJ, Williams J, Castro L, et al. The efficacy of starting postterm antenatal testing at 41 weeks as compared with 42 weeks of gestational age. Am J Obstet Gynecol 1988;159:550. DOI: 10.1016/ s0002-9378(88)80005-x.

23. Alfirevic Z, Walkinshaw SA. A randomised controlled trial of simple compared with complex antenatal fetal monitoring after 42 weeks of gestation. Br J Obstet Gynaecol 1995;102:638. DOI: 10.1111/j.14710528.1995.tb11402.x.

24. American College of Obstetricians and Gynecologists. Practice bulletin no. 146: management of late-term and post term pregnancies. Obstet Gynecol 2014;124:390. DOI: 10.1097/01.AOG.0000452744.06088.48.

25. Kistka ZA, Palomar L, Boslaugh SE, et al. Risk for post term delivery after previous post term delivery. Am J Obstet Gynecol 2007;196:241. e1. DOI: 10.1016/j.ajog.2006.10.873.

26. Kortekaas JC, Kazemier BM, Ravelli AC, et al. Recurrence rate and outcome of post term pregnancy, a national cohort study. Eur J Obstet Gynecol Reprod Biol 2015;193:70. DOI: 10.1016/j.ejogrb.2015.05.021.

27. Verma V, Kanti V, Shree P. Maternal and fetal outcome in post term pregnancy. Int J Reprod Contracept Obstet Gynecol 2017;6(7):28972899. DOI: $10.18203 / 2320-1770 . i j r c o g 20172632$.

28. Kandalgaonkar VP, Kose V. Fetomaternal outcome in post dated pregnancy. Int J Reprod Contracept Obstet Gynecol 2019;8(5):18991906. DOI: 10.18203/2320-1770.ijrcog20191940.

29. Singh N, Misra D, Srivastava S. Postdated pregnancy: its maternal and fetal outcome. Int J Reprod Contracept Obstet Gynecol 2020;9(8):3223-3227. DOI: 10.18203/2320-1770.ijrcog20203299.

30. Akhter $P$, Sultana $M$, Hoque $M$, et al. Maternal outcome of prolonged pregnancy. J Bangladesh Coll Phys Surg 2014;32(2):66. DOI: 10.3329/ jbcps.v32i2.26033. 